\title{
Analisis Kinerja Kompresi Citra Digital dengan Komparasi DWT, DCT dan Hybrid (DWT-DCT)
}

\author{
Aditya Mahmud Faza ${ }^{1}$, Cepy Slamet ${ }^{2}$, Dian Nursantika ${ }^{3}$ \\ 1,2,3 Jurusan Teknik Informatika, Fakultas Sains dan Teknologi \\ Universitas Islam Negeri Sunan Gunung Djati Bandung \\ Jl. A.H. Nasution 105, Bandung 40614 Indonesia \\ ${ }^{1}$ aditya.mahmud@student.uinsgd.ac.id, ${ }^{2}$ cepy_lucky@uinsgd.ac.id, ${ }^{3}$ dianursantika@yahoo.com
}

\begin{abstract}
Penelitian ini merupakan penelitian tentang penerapan transformasi diskrit kosinus (DCT), transformasi wavelet diskrit (DWT), dan hybrid sebagai penggabungan dari kedua transformasi sebelumnya dalam proses kompresi data citra digital. Proses kompresi dilakukan untuk menekan konsumsi sumber daya memory, mempercepat proses transmisi citra digital. Proses kompresi yang dilakukan dapat menghasilkan nilai mean square, peak signal to noise ratio dan waktu yang dibutuhkan untuk proses kompresi dari masing-masing transformasi. Nilai tersebut sebagai parameter untuk tahap komparasi kompresi sehingga pengguna dapat menentukan kinerja kompresi dari setiap transformasi dan dapat menentukan jenis transformasi yang paling baik digunakan untuk proses citra digital.
\end{abstract}

Kata kunci - DCT, DWT, hybrid, peak signal to ratio, mean square error

\section{Pendahuluan}

Salah satu teknologi pengolahan citra digital yang telah berkembang ialah teknologi kompresi. Kompresi citra digital merupakan upaya untuk melakukan transformasi terhadap data atau simbol penyusun citra digital menjadi data atau simbol lain. Kompresi harus dilakukan secara efektif, sehingga citra digital yang dihasilkan setelah proses kompresi mempunyai ukuran yang lebih kecil dibandingkan sebelum proses kompresi serta tanpa mengurangi informasi utama.

Bentuk citra yang sudah berkembang menjadi digital dan memiliki kualitas semakin baik menuntut manusia untuk menyediakan kapasitas media penyimpanan yang tidak sedikit untuk citra tersebut.. Menurut Sutoyo (2009) mengenai hal kebutuhan memori sebagai kriteria pengukuran citra digital bahwa biasanya semakin besar presentasi pemampatan, semakin kecil kebutuhan memori yang diperlukan sehingga kualitas citra semakin berkurang dan sebaliknya, semakin kecil presentasi citra yang dimampatkan, semakin bagus kualitas hasil kompresi. Memperkecil ukuran dari citra yang baik adalah metode yang dikembangkan dalam kompresi citra.[1]

Menurut Sutoyo (2009), citra hasil kompresi yang baik adalah yang cocok dengan kebutuhan pengiriman dan penyimpanan [1]. Biasanya transmisi ini banyak dilakukan dengan cara pengiriman dalam jaringan. Citra ditransmisikan dalam jaringan untuk menyampaikan informasi terhadap orang yang membutuhkannya. Sebuah citra yang memiliki banyak informasi atau kapasitas besar akan ditransmisikan dalam jaringan dengan membutuhkan sumber daya yang besar juga.

Komparasi kompresi citra digital merupakan sebuah cara pembuktian untuk menentukan teknik kompresi mana yang lebih baik untuk digunakan. Diantara banyaknya teknik kompresi dengan metode transformasi seperti DCT (Discrete Cosine Transform), DWT (Discrete Wavelet transform) dan hybrid umumnya memiliki tujuan yang sama, namun dengan berbagai teknik kompresi yang digunakan, maka berbeda pula hasil kompresinya.. Oleh sebab itu, diperlukan komparasi terhadap teknik kompresi agar dapat menentukan teknik kompresi yang digunakan sesuai dengan tujuan yang ingin dicapai.

\section{TINJAUAN PUSTAKA}

\section{A. Discrete Cosine Transform}

DCT adalah sebuah teknik mengubah sinyal ke dalam komponen frekuensi dasar. Keunggulan DCT walaupun image dikompresi dengan lossy compression tidak akan menumbulkan kecurigaan karena metode ini terjadi di domain frekuensi di dalam image, bukan pada spasial sehingga tidak akan ada perubahan yang terlihat pada image. Sedangkan kekurangannya, DCT tidak tahan terhadap perubahan suatu objek dikarenakan pesan mudah dihapus karena lokasi penyisipan data dan pembuatan data dengan metode DCT diketahui.

\section{1) Discrete Cosine Transform - 1 Dimension}

DCT dari sederet bilangan real $\mathrm{d}(\mathrm{x}), \mathrm{x}=0, \ldots, \mathrm{n}-$ 1, dirumuskan sebagai [2]: 
Barisan $\mathrm{d}(\mathrm{x})$ diperoleh lagi dari transformasinya $\mathrm{d}(\mathrm{u})$ dengan menggunakan Inverse Discrete Cosine Transform (IDCT), dirumuskan sebagai berikut [2]:

$$
d(X)=\sqrt{\frac{2}{n}} \sum_{x=0}^{n-1} d(u) C(u) \cos \left(\frac{(2 x+1) u \mu}{2 n}\right)
$$

Keterangan: $u=0, \ldots . n-1$

Dimana $C(u)=2-0.5$ untuk $u=0$

1 untuk lainnya

Persamaan di atas menyatakand sebagai kombinasi linier dari basis vector. Koefisien adalah elemen transformasi $d$, yang mencerminkan banyaknya setiap frekuensi di dalam masukkan $d$.

\section{2) Discrete Cosine Transform - 2 Dimension}

DCT-2D merupakan perbandingan dari DCT-1D, maka transformasi diskrit dapat dinyatakan dalam bentuk persamaan. Dalam algoritma JPEG, sampel gambar $I(i, j)$ dibagi menjadi blok $8 \times 8$. Setiap blok ditransformasi menjadi $8 \times 8$ matriks koefisien DCT. Definisi matematis dari masing-masing blok koefisien didefinisikan sebagai [3]:

$$
\begin{aligned}
& d_{u, v} \\
& =\frac{C_{u} C_{v}}{4} \sum_{i=0, j=0}^{7} I_{i, j} \cos \left(\frac{(2 i+1) u \pi}{16}\right) \cos \left(\frac{(2 j+1) v \pi}{16}\right)
\end{aligned}
$$

Dan output dari invers DCT (IDCT) adalah:

$I_{i, j}=\frac{C_{u} C_{v}}{4} \sum_{u=0, v=0}^{7} d_{u, v} \cos \left(\frac{(2 i+1) u \pi}{16}\right) \cos \left(\frac{(2 j+1) v \pi}{16}\right)$

Dimana Cw didefinisikan sebagai :

$$
C_{w}=\left\{\begin{array}{l}
\frac{1}{\sqrt{2}}, \text { if } w=0 \\
1, \text { otherwise }
\end{array}\right.
$$

Seperti ditunjukkan pada gambar di bawah ini, matriks koefisien dari blok output DCT disusun sebagai bentuk zig-zag.

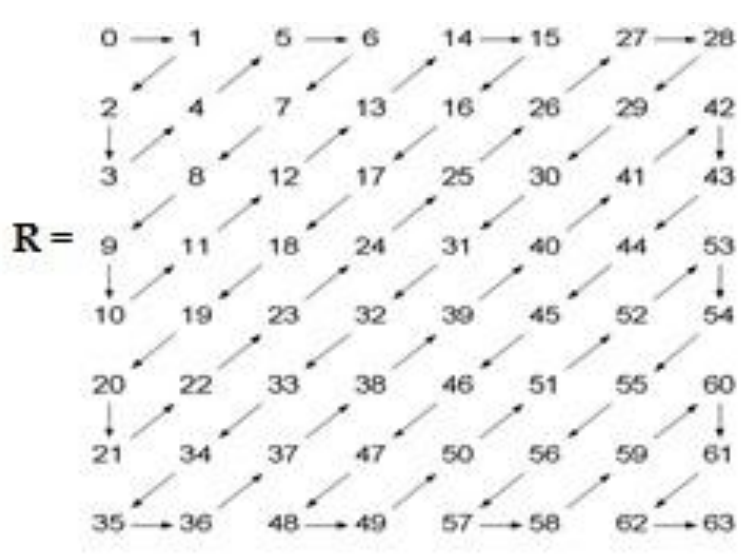

Gambar 1. Matriks koefisien DCT 8x8

\section{B. Discrete Wavelet Transform}

Wavelet merupakan keluarga dari turunan fungsi tunggal yang ditranslasikan dan didilatasikan [4]. Bentuk umum dari fungsi wavelet adalah:

$$
\psi^{n, h}-|u|^{-1 / 2} \psi\left(\frac{t-b}{a}\right)
$$

$\psi$ disebut wavelet induk (mother wavelet) dan digunakan untuk mendapatkan semua turunannya. Pilihan umum untuk $a$ dan $b$ adalah $a=2^{m}, b=n 2^{m}, n, m \in Z$, dengan $n$ dan $m$ merupakan indek skala dan indek translasi, sehingga didapatkan

$$
\psi_{m, n}(t)=2^{-m / 2} \psi\left(2^{-m} t-n\right)
$$

DWT selain menggunakan fungsi wavelet, juga menggunakan dungsi untuk penghalusan citra (image smoothing)[6]. Fungsi skala didilatasikan dan ditranslasikan sebagaimana persamaan fungsi wavelet, sehingga didapatkan

$$
\phi_{m, n}(t)=2^{-m / 2} \phi\left(2^{-m / 2} t-n\right)
$$

Teori analisis revolusi banyak menyatakan baha $\mathbf{- 1}=$ $\boldsymbol{V}_{\boldsymbol{m}} \oplus \boldsymbol{W}_{\boldsymbol{m}}$. Ini berarti bahwa $\boldsymbol{I}$ adalah komplemen orthogonal untuk dalam -1. Terdapat vektor dalam vektor -1, sehingga vektor dan -1 mempunyai ruang waktu yang berbeda[5].

Untuk menghubungkan vektor tersebut digunakan suatu filter $t$ dengan fungsi skala dan filter $l$ dengan fungsi wavelet sehingga,

$$
\begin{aligned}
& t=\sum_{n} h(n) \sqrt{2 \phi(2 t-n)} \\
& l=\sum_{n} y(n) \sqrt{2 \psi(2 l-n)}
\end{aligned}
$$

Proses dekomposisi suatu sinyal ke dalam aprokmasi dan detail, seperti proyeksi $x$ ke $V_{m}$ dan $\mathrm{W}_{\mathrm{m}}$. Proses ini dapat di peroleh dengan melewatkan koefisien pada suatu filter melalui proses sub-sampling. Karena citra merupakan du dimensi, sehingga dekomposisi dilakukan terhadap baris dan kolom, seperti pada Gambar 2. 


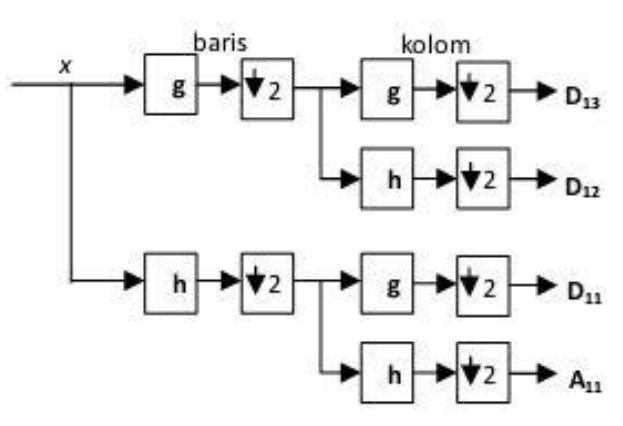

Gambar 2. Dekomposisi Bidang 2 Dimensi

Proses dekomposisi sinyal $x$ dapat dilakukan proses kebalikannya, yaitu dengan merekonstruksi sinyal $x$ dari aproksimasi dan detailnnya. Rekonstruksi dilakukan dengan melewatkan aprokmasi dan detail pada filter dan menggabungkannya.

\section{Parameter}

1. Mean Square Error (MSE)

MSE adalah nilai error kuadrat antara citra asli dengan citra terkompresi. Nilai rata-rata darau yang tinggi menandakan tingkat kinerja kompresi yang tinggi. MSE bernilai 0, maka citra terkompresi dengan citra asli memiliki nilai sama pada setiap pixelnya dan dalam hal ini menandakan kompresi tidak ada. Nilai MSE didapatkan dari persamaan:

$$
M S E=\frac{1}{M N} \sum_{x=1}^{M} \cdot \sum_{y=1}^{N}(S(x y)-C(x y))^{2}
$$

Keterangan :

$$
\begin{array}{ll}
\text { - } & \mathrm{x} \text { dan } \mathrm{y}=\text { koordinat citra digital } \\
\text { - } & \mathrm{M} \text { dan } \mathrm{N}=\text { dimensi dari citra digital } \\
\text { - } & \mathrm{S}_{\mathrm{xy}}=\text { stego } \text { citra digital } \\
\text { - } & \mathrm{C}_{\mathrm{xy}}=\text { cover } \text { citra digital }
\end{array}
$$

\section{Peak Signal to Noise Ratio (PSNR)}

PSNR digunakan untuk mengukur kualitas citra, selain menggunakan human viual. Parameter PSNR menunjukan perbandingan antara nilai maksimum dari sinyal yang diukur dengan besarnya derau yang berpengaruh pada sinyal tersebut, diukur dalam satuan decibel (dB)[5]. Pada penelitian ini, PSNR digunakan untuk mengetahui kualitas citra hasil kompresi.

Untuk menentukan nilai dari PSNR, terlebih dahulu harus diketahui nilai rata-rata kuadrat dari error yaitu menggunakan MSE. Semakin besar parameter PSNR berarti semakin mirip dengan citra asli, sedangkan nilai MSE akan semakin kecil. Rumus dari PSNR terdapat pada persamaan sebagai berikut:

$$
P S N R=10 \cdot \log \left(\frac{M A X^{2}}{M S E}\right)=20 \cdot \log \left(\frac{M A X_{i}}{\sqrt{M S E}}\right)
$$

Notasi $M A X_{i}$ menunjukan nilai maksimum piksel, $m$ dan $n$ adalah panjang dan lebar citra (dalam piksel), (ij) menunjukan koordinat masing-masing piksel, $w$ sebagai nilai intensitas cover image, dan $w^{\prime}$ adalah nilai intensitas citra hasil kompresi.

\section{Metode Penelitian}

Data yang digunakan dalam penelitian ini ialah citra diam (still image) berwarna dengan berjumlah 150 citra, diantaranya citra yang memiliki resolusi 1024 x 1024 pixel berjumlah 100 buah citra dan citra dengan resolusi di atas 1024 x 1024 berjumlah 50 buah citra. Semua citra tersebut berformat file jpg.

Peralatan pendukung penelitian adalah seperangkat komputer dengan processor Intel Core i3-2328M 2.20 $\mathrm{GHz}$, memori 2 GB DDR2, harddisk $250 \mathrm{~GB}$. Perangkat lunak pengolahan citra menggunakan Eclipse Mars.1.

Sesuai dengan judul dan tujuan dair penelitian, bahwasanya teknik yang digunakan dalam kompresi citra ialah teknik transformasi dengan menggunakan algoritma DCT, DWT dan Hybrid. Berikut dapat dilihat diagram alir dari proses kompresi :

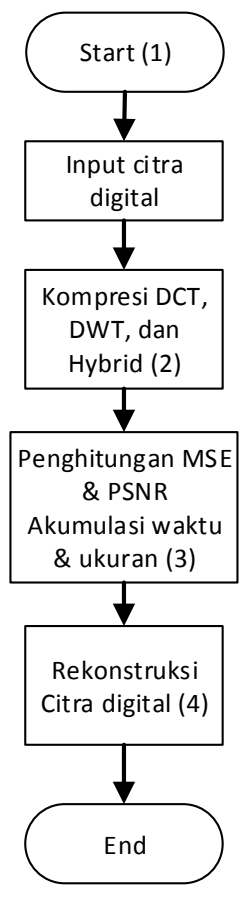

\section{Start}

Gambar 3. Diagram Alir Sistem Kompresi

Pada tahap ini, yang pertama kali dilakukan adalah menjalankan program yang telah dibuat pada Eclipse. Setelah itu dilakukan proses input data berupa citra digital yang telah dipersiapkan. Pada sistem ini, citra yang dilakukan uji coba adalah citra yang menjadi sample dan yang telah dijelaskan pada alinea sebelumnya. Sumber keseluruhan citra uji berasal dari image of google dengan keyword : "citra jpg 2014 x 1024" dan "citra jpg wallpaper full colour". 


\section{Kompresi DCT, DWT dan Hybrid}

Pada tahap ini, dilakukan proses kompresi menggunakan semua algoritma secara bergantian untuk 1 citra. Pertama melakukan kompresi citra dengan algoritma DCT terhadap citra uji, kemudian melakukan kompresi dengan algoritma DWT terhadap citra uji dan begitupu dengan algoritma hybrid, sehingga masing-masing memiliki hasil kompresi citra yang berbeda atas citra uji.

\section{Penghitungan dan Akumulasi}

Pada tahap ini dilakukan proses penghitungan nilai dari MSE dan PSNR untuk masing - masing algoritma. Penghitungan tersebut dilakukan dengan cara membandingkan nilai dari citra hasil kompresi dari masing-masing algortima dengan citra uji yang sama. Nilai MSE dan PSNR digunakan untuk proses analisis citra kompresi sehingga dapat dibandingkan dan dapat pula menentukan algoritma terbaik untuk kompresi data citra.

Selain tahap penghitungan nilai MSE dan PSNR, terdapat proses akumulasi waktu dan ukuran citra digital. Fungsi daripada proses ini ialah agar dapat menentukan tingkat kinerja algoritma dalam proses kompresi. Waktu untuk satu algoritma dimulai ketika proses kompresi dengan algoritma tersebut dimulai dan berakhir ketika proses kompresi selesai, dan begitupun dengan algoritma lainnya. Akumulasi waktu dapat menentukan tingkat kinerja kompresi, semakin lama waktu yang dibutuhkan untu kompresi menandakan tingkat knerja kompresi yang tinggi. Selain aktu, ada pula akumulasi ukuran citra terkompresi. Fungsi akumulasi dari ukuran file citra erat kaitannya dengan tingkat optimasi memori file dan transmisi data citra. Semakin besar rasio kompresi menandakan tingkat optimasi memori file yang baik sehingga citra yang dihasilkan dapat ditransmisikan dengan cepat.

\section{Rekonstruksi Citra Digital}

Proses terakhir dimana didapatkan citra keluaran yang tersimpan dalam format yang sama yaitu jpg. Dari hasil tersebut dapat dilihat ukuran file citra berdasarkan blokblok yang telah di uji cobakan agar dapat melakukan analisis terhadap optimasi memori file dari citra hasil kompresi.

\section{PEMBAHASAN}

Hasil uji coba proses kompresi dengan ketiga algoritma menunjukan perubahan ukuran yang berbeda, waktu yang dibutuhkan berbeda pula, begitupun dengan nilai MSE dan PSNR untuk satu citra uji. Hasil kompresi berdasarkan kesamaan blok yaitu sama-sama menggunakan blok $8 \times 8$. Dilakukan analisis terhadap semua parameter yang telah ditetapkan yang hasil uji ini dugunakan untuk menarik kesimpulan pada penelitian ini.

Berikut contoh 2 hasil uji kompresi dari citra dengan pembagian kategori dari semua sample yaitu citra dengan resolusi 1024 x 1024 dengan ukuran di bawah 1 MB dan citra dengan resolusi di atas 1024 x 1024 dengan ukuran di atas $1 \mathrm{MB}$ :

Tabel 1. Hasil uji coba

\begin{tabular}{|c|c|c|c|c|c|}
\hline & Algo & $\begin{array}{c}\text { MSE } \\
(\mathrm{dB})\end{array}$ & $\begin{array}{c}\text { PSNR } \\
(\mathrm{dB})\end{array}$ & $\begin{array}{c}\text { Waktu } \\
(\text { detik })\end{array}$ & $\begin{array}{c}\text { Rasio } \\
(\%)\end{array}$ \\
\hline \multirow{2}{*}{$\begin{array}{c}\text { Rata-rata } \\
\text { (150 data uji) }\end{array}$} & DCT & 28.02 & 36.03 & 162.21 & 63.38 \\
\cline { 2 - 6 } & DWT & 29.55 & 38.58 & 2.71 & 67.15 \\
\cline { 2 - 6 } & Hybrid & 34.03 & 25.72 & 2.94 & 70.51 \\
\hline
\end{tabular}

Dari hasil rata-rata dari 150 data citra uji, manghasilkan nilai MSE dari ketiga algoritma. Nilai MSE yang baik ialah memiliki nilai paling rendah, karena semakin rendah nilai MSE maka nilai rata-rata kerusakan tidak besar dan citra tidak banyak kehilangan informasi. Sedangkan nilai PSNR yang baik ialah memiliki nilai tertinggi, karena semakin tinggi nilai PSNR maka nilai kualitas semakin tinggi dan citra terkompresi semakin mendekati citra aslinya. Berikut grafik dari nilai MSE dan PSNR hasil kompresi:

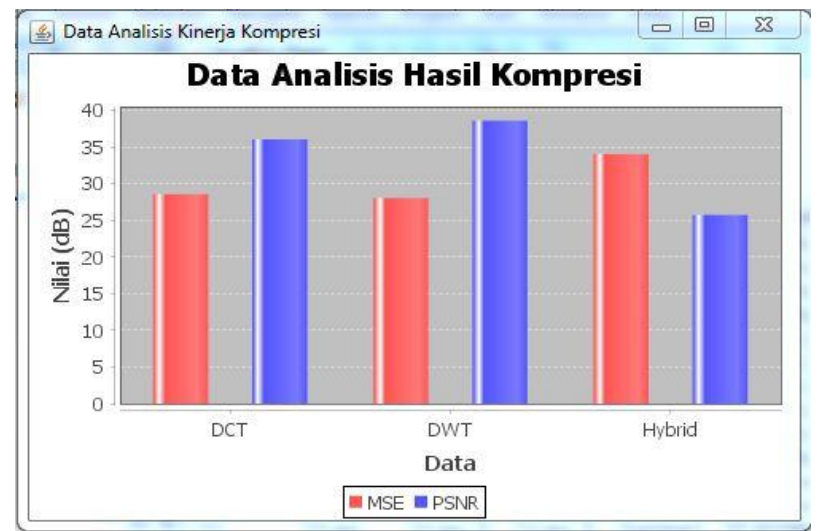

Gambar 4. Grafik Nilai Rata-rata MSE dan PSNR

Menjawab permasalahan terkait optimasi memori dan transmisi data citra erat kaitannya dengan besaran rasio kompresi yang dihasilkan. Berikut grafik dari rata-rata nilai rasio kompresi dari semua algoritma :

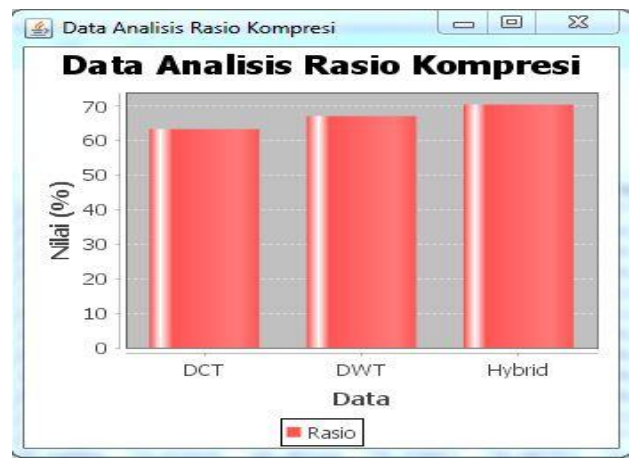

Gambar 5. Grafik Nilai Rata-rata Rasio Kompresi

Selain MSE, PSNR dan rasio kopresi, terdapat parameter waktu yang dapat menentukan tingkat kinerja kompresi untuk masing-masing algoritma. Semakin lama 
perolehan waktu dalam proses kompresi menandaka proses yang membutuhkan tenaga yang tinggi sama dapat diartikan bahwa algortima tersebut membutuhkan kinerja yang tinggi pula. Berikut grafik perbandingan waktu dari hasil rata-rata kompresi :

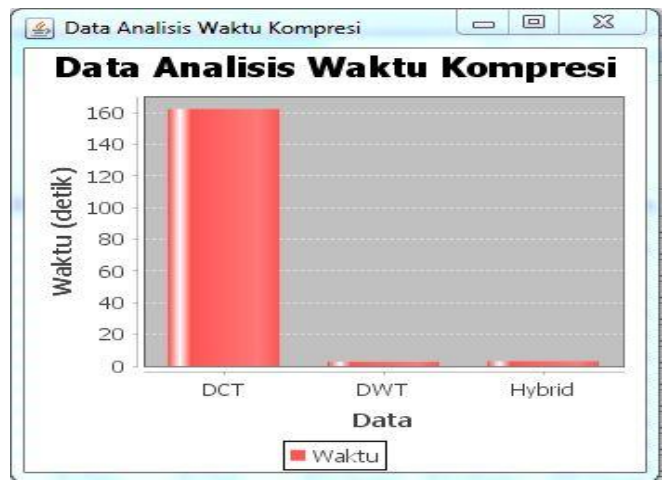

Gambar 5. Grafik Nilai Rata-rata Rasio Kompresi

Perolehan waktu paling tinggi terdapat pada algoritma DCT dengan perolehan rata-rata waktu sebesar 162.21 detik, lalu dilanjutkan algoritma Hybrid dengan perolehan rata-rata waktu sebesar 2.94 detik dan yang terakhir adalah algoritma DWT dengan perolehan rata-rata waktu sebesar 2.71 detik.

\section{KESIMPULAN}

Berdasarkan penelitian yang telah dilakukan, maka dapat disimpulkan beberpa hal sebagai berikut:

1. Algoritma Discrete Cosine Transform (DCT), Discrete Wavelet Transform (DWT) dan Hybrid (DCT-DWT) dapat mengkompresi file citra digital dengan ekstensi file jpg;

2. Semakin rendah nilai MSE menandakan semakin baik kulitas citra terkompresi. Hasil analisisi pada bab sebelumnya, algoritma DWT memiliki nilai MSE terendah dengan nilai rata-rata MSE sebesar $28.02 \mathrm{~dB}$, dan DCT memiliki nilai terendah kedua dengan nilai MSE sebesar $28.55 \mathrm{~dB}$;

3. Semakin tinggi nilai PSNR maka semakin baik kualitas citra terkompresi. Hasil analisis mengenai nilai PSNR pada bab sebelumnya, algoritma DWT memiliki nilai PSNR tertinggi dengan nilai rata-rata PSNR sebesar $38.58 \mathrm{~dB}$, dan DCT memiliki nilai tertinggi kedua dengan nilai PSNR sebesar $36.03 \mathrm{~dB}$;

4. Tingkat efesien memori file hasil kompresi diukur dari besarnya rasio kompresi yang dihasilkan. Semakin besar nilai rasio kompresi menandakan semakin efisien memori hasil kompresi. Algoritma Hybrid memiliki nilai rata-rata rasio kompresi tertinggi dengan nilai sebesar $70.51 \%$. Besarnya prosentase kompresi Hybrid menjadikan hasil kompresi memiliki ukuran file paling kecil.

5. Lamanya waktu yang dibutuhkan kompresi menandakan proses kinerja kompresi yang membutuhkan energi yang besar. Dalam kasus perbandingan algoritma, waktu terpendek menjadi waktu terbaik untuk dipilih. Waktu terpendek untuk proses kompresi ditunjukan oleh algoritma DWT dengan rata-rata waktu kompresi 2.71 detik. Waktu tercepat kedua didapat oleh algoritma Hybrid dengan rata-rata waktu kompresi 2.94 detik.

Berdasarkan permasalahan penelitian mengenai efisiensi media penyimpanan dan transmisi citra digital, maka dapat disimpulkan bahwa algoritma yang tapat untuk dipilih adalah algoritma dengan nilai rasio kompresi tertinggi yaitu algoritma Hybrid, sedangkan untuk metode terbaik dilihat dari nilai MSE yang rendah, PSNR yang tinggi, rasio kompresi yang tinggi dan waktu yang paling cepat. Algoritma memenuhi syarat tersebut yaitu algoritma DWT.

\section{REFERENSI}

[1] Sutoyo, T, dkk. 2009.Teori Pengolahan Citra Digital. Yogyakarta Penerbit Andi.

[2] Shofiyah, "Studi Perbandingan Kompresi Menggunakan Metode Descrete Cosine Transform (DCT) dan Descrete Wavelet Transform (DWT) pada Citra Digital", Skripsi Teknik Informatika Universitas Islam Negeri Maulana Malik Ibrahim, Malang, 2010.

[3] Chung-Ming Kuo, Nai-Chung Yang, Chih-Shan Liu, Jing-Yan Li, adn Fu-Yan Chen, "Global Image Enhancement in DCT Domain”, IEEE, pp.521-525, 2010.

[4] Sjoblom, Erik. (2002), Compression of Medical Image Stacks using Wavelets and Zero-Tree Coding,Thesis, English, Linkoping University.

[5] Philips, W. J. (2003), Wavelets and Filter Banks Course Notes.

[6] Pressman, Roger S. 2002. Rekayasa Perangkat Lunak : Pendekatan Praktisi (Buku Satu). Yogyakarta : Andi Offset.

[7] Priyanta, F. 2011. Pemrograman Android untuk Pemula. Jakarta : Pembuka Cakrawala.

[8] Safaat H. Nazruddin. 2012. Pemrograman Aplikasi Mobile Smartphone dan Tablet PC berbasis Android. Bandung : Informatika.

[9] Nugroho, Adi. 2010. Rekayasa Perangkat Lunak Berbasis Objek dengan Metode USDP. Yogyakarta : Andi.

[10] Al Fatta, Hanif. 2007. Analisis dan Perancangan Sistem Informasi. Yogyakarta: Andi.

[11] Neta, Maria Roslin Apriani. 2013. Perbandingan Algoritma Kompresi Terhadap Objek Citra Menggunakan JAVA. 